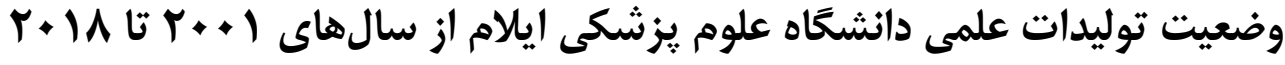

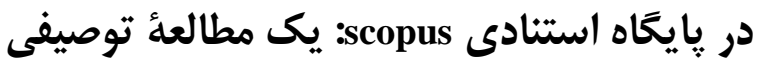

\author{
"يروانه رنجبر " \\ 1) كروه علمرسنبح، دإنشكاه علوم يزشكى إيلام، إيلام، ايرلن

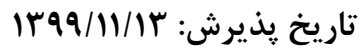

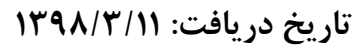

\section{جيكيده}

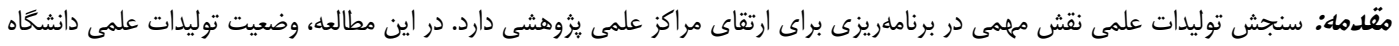

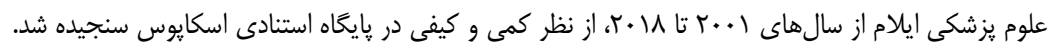

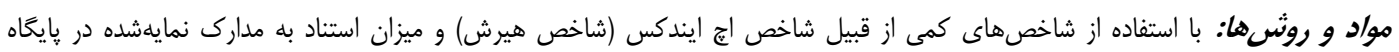

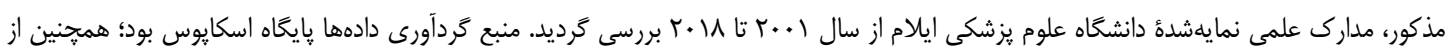

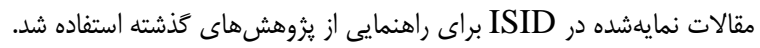

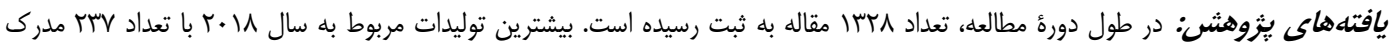

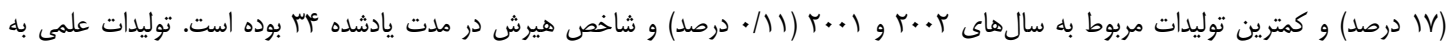

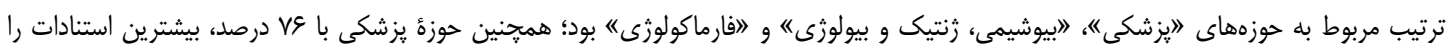

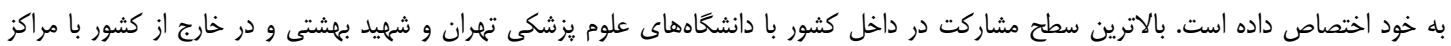

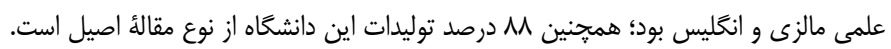

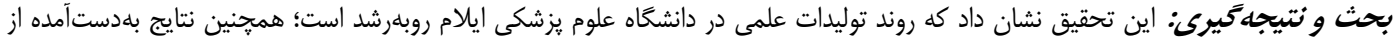

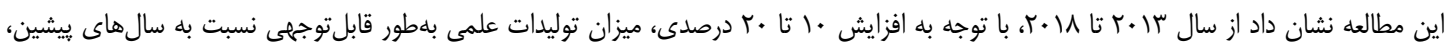
رشد بالا و خشميرى داشته است.

وازههاى كليدى: علمسنجى، توليدات علمى، پايخاه استنادى اسكايوس، دانشگاه علوم يزشكى ايلام، شاخص هيرش

Email: rparsi2013@gmail.com

" م نويسندة مسئول: كروه علمسنجى، دانشكاه علوم بزشكى ايلام، ايلام، ايران

Copyright $\odot 2019$ Journal of Ilam University of Medical Science. This is an open-access article distributed under the terms of the Creative Commons Attribution international 4.0 International License (https://creativecommons.org/licenses/by-nc/4.0/) which permits copy and redistribute the material, in any medium or format, provided the original work is properly cited. 
است كه همكى بلهنظور بررسى وضعيت كنونى توليد

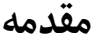
علم بوده است و ازآنجاكه با مشخص شدن برسن وضعيت

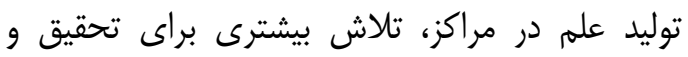
يزوهش صورت مى يَرد؛ بنابراين، در اين يزوهش نيز بيز

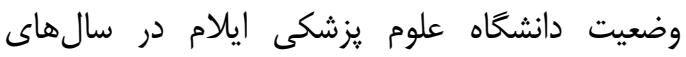
متوالى بررسىشده است. تاكنون جنين تحقيقى با هدف

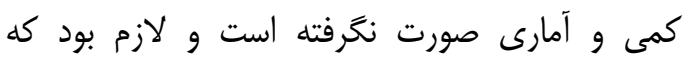

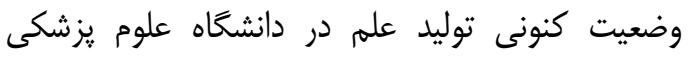

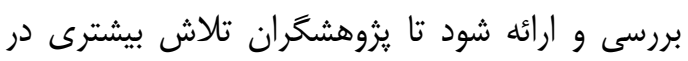

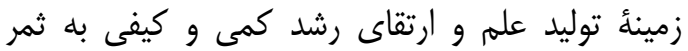

\section{مواد و روشهاندان}

در يك يزوهش مقطعى، همأ توليدات دانشكاه

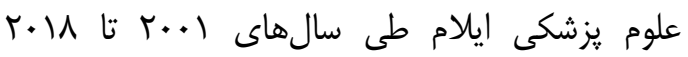
بررسى شد. دادهها از پِايخاه اطلاعاتى اسكايوس تحت يوشش الزوير استخراج كرديد. ابتدا همأ وابستخىهاى سازمانى مشخص شد و عبارت دانشكاه علوم يزشكى إنى إنى ايلام بلهنوان كليدوازٔه اصلى جستجو انتخاب كرديد. در مرحلئ اول، تعداد توليدات در سالهاى مدنظر بررسى و سپيس تحليل استنادى بر روى توليدات با

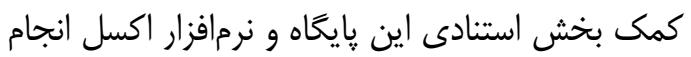
شد؛ همجنين توليدات از نظر موضوع، مشاركت با ساير إنيا سازمانها، مقالات يركاربرد و شاخص هيرش بررسى گرديد كه از ويزَى هاى علمسنجى هستند. دادههاى

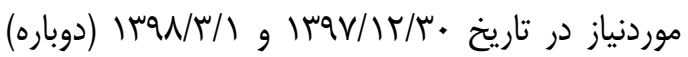
استخراج و بررسى شده است.

در طى دوره بررسى، تعداد

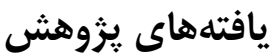

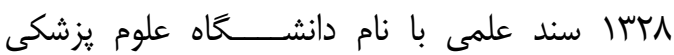
ايلام در پايعاه استـــنادى اسكايوس نمايه شده بود.

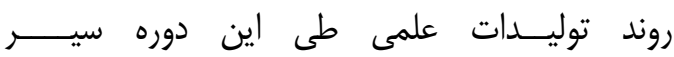

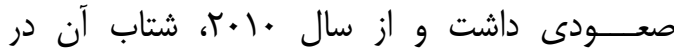
مقايســـهـ با سالهاى ييش از آن، بيشتر بود.

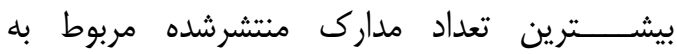

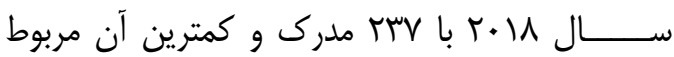

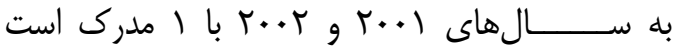

$$
\text { (شكل شمارة ()). }
$$

رشد و توسعة علوم از دهأ •و19 به بعد و بهكارگيرى سنجش و اندازهيرى در عله، تحولات نوينى را در اين عرصه ايجاد كرد و دامنُٔ اين تحولات

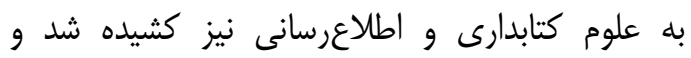

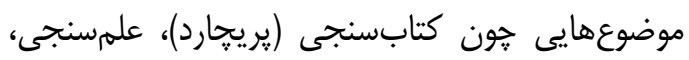

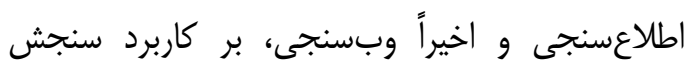
تأكيد دارند. در تحقيقى با عنوان \از كتابسنجى تا وبسنجى:

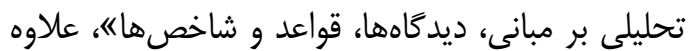
بر بيان ساير روشهاى اندازميرى در حوزه كتابدارى و اطلاعرسانى، مبحث علمسنجى نيز تشريح شده است.

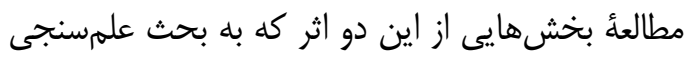
اختصاص دارد، در درى مباحث نظرى اين حوزه مؤثر است، بلويزه از اين نظر كه عمده منابع منتشرشده در در درائ

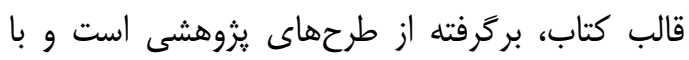

رويكرد كاربردى به حوزهُ علمسنجى يرداختهانهاند (1).

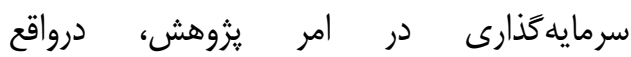
سرمايهذذارى براى توليدات علمى است و شرايطى رايه

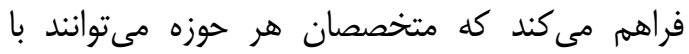

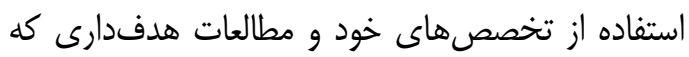
انجام مىدهند، اطلاعات نوينى را براى بهرهمند شدن

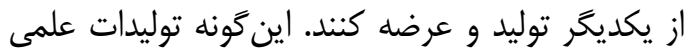

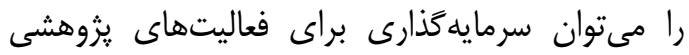
بلهمار آورد. رشد كمى و كيفى مقالات از ماردمات مهرترين شاخصهاى ارزشيابى افراد، دانشعاهها و درنهايت آرايت

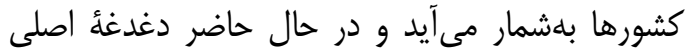

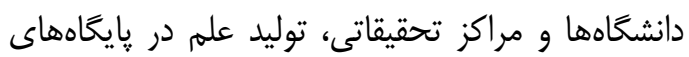

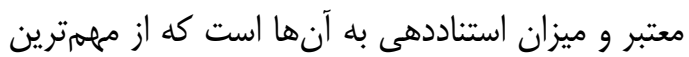

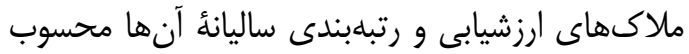
مىشود. اين مطالعه، با هدف بررسى توليدات علمى

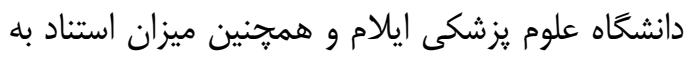

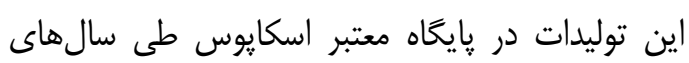

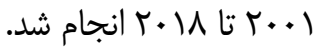

يزوهشهاى فراوانى درباره وضعيت توليدات دانشخاهها مراكز، مؤسسات آموزش عالى صورت كرفيته 


\section{وضعيت توليا علم دانشعاه علوم بز شيكى ايلام در

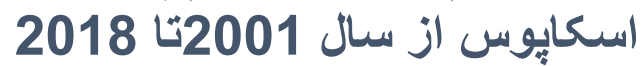

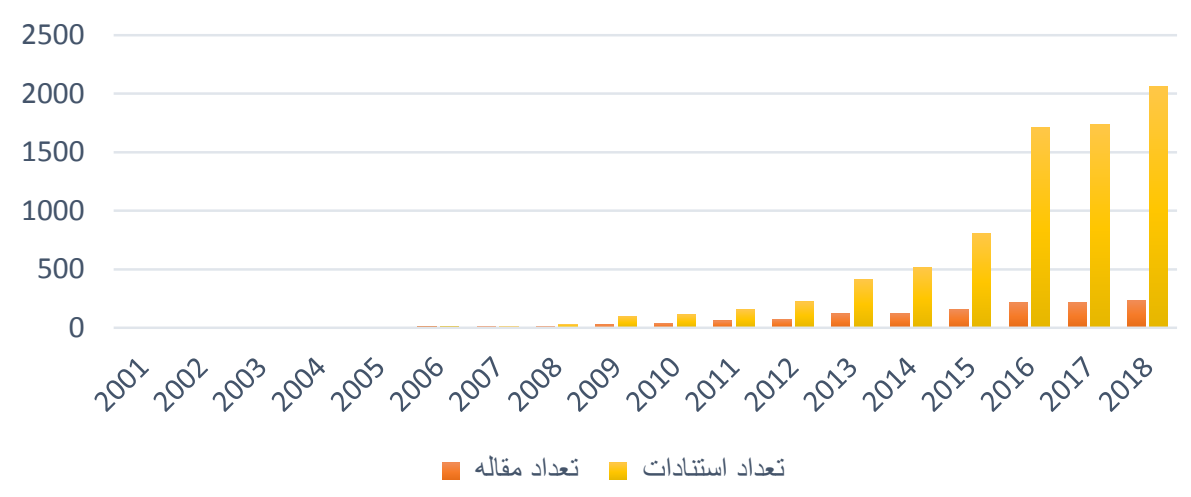

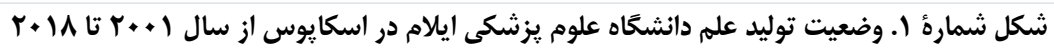

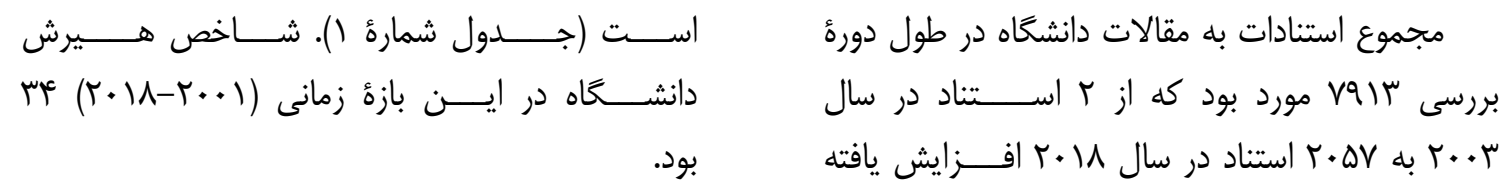

\begin{tabular}{|c|c|}
\hline تعداد (درصد) & نوع مدرك \\
\hline$(1.91$ & مقالئ اصيل \\
\hline 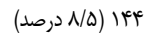 & 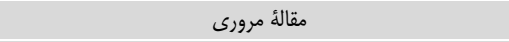 \\
\hline 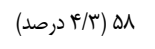 & نامه به سرديير \\
\hline 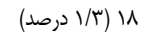 & مقالات زير حاب \\
\hline 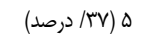 & مقالات Erratum \\
\hline r r(r/• درصد) & يادداشتها \\
\hline 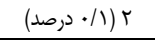 & مقالات ردشده و بررسىهاى كوتاه و يادداشتها و فصلى از كتاب \\
\hline
\end{tabular}

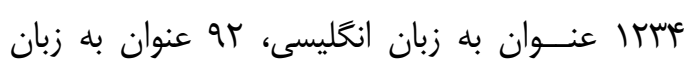

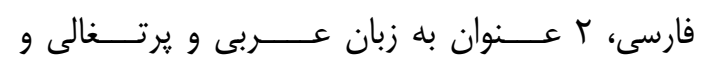

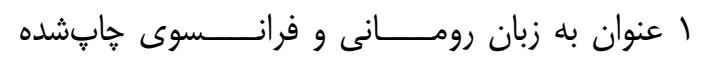

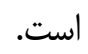

در جدول شماره ك، توزيع فراوانى مدارك و تعداد استناد برحسب نوع مدرك نشان دادهشده است. مقالات

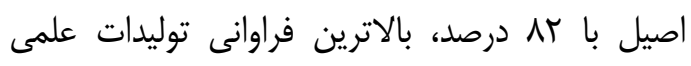

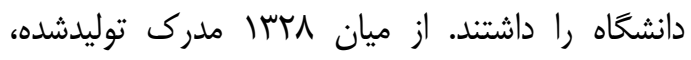




\begin{tabular}{|c|c|c|c|}
\hline 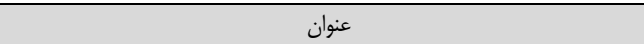 & رتبأ مجله در سايمكو & SJR & 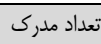 \\
\hline Journal Of Clinical And Diagnostic Research & $9 \% / 111$ & 0.352 & st \\
\hline Iranian Red Crescent Medical Journal & $|r / \Lambda F|$ & 0.42 & سז \\
\hline Der Pharmacia Lettre & $1 \cdot N / N F$ & 0.139 & ו \\
\hline Iranian Journal Of Obstetrics Gynecology And Infertility & $1 \cdot V / \backslash \notin \Lambda$ & 0.266 & rr \\
\hline Asian Pacific Journal Of Cancer Prevention & 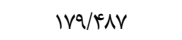 & 0.616 & r) \\
\hline Iranian Journal Of Public Health & rav/squ & 0.33 & M \\
\hline Journal Of Pharmaceutical Sciences And Research & $\mid r \cdot / I V e^{c}$ & 0.153 & 18 \\
\hline Koomesh & HTN/AFi & 0.246 & 10 \\
\hline Comparative Clinical Pathology & $r \varepsilon / r \Delta$ & 0.374 & if \\
\hline Desalination And Water Treatment & ri/q) & 0.398 & if \\
\hline Journal Of Chemical And Pharmaceutical Sciences & $|f| / M A$ & 0.148 & If \\
\hline Journal Of Pure And Applied Microbiology & VN/QD & 0.123 & if \\
\hline Acta Medica Iranica & $19 N / \lambda+1$ & 0.34 & it \\
\hline Acta Microbiologica Et Immunologica Hungarica & q q & 0.352 & 11 \\
\hline Gastroenterology And Hepatology From Bed To Bench & $I K N / D$. & 0.704 & 11 \\
\hline Iranian Journal Of Pediatrics & $\| E N / T R$ & 0.428 & 11 \\
\hline Tehran University Medical Journal & $\Lambda F / \& \& \Delta$ & 0.139 & 11 \\
\hline Archives Of Iranian Medicine & $11 \cdot / \lambda+i$ & 0.61 & 1. \\
\hline Burns & $q / V V$ & 1.044 & 1. \\
\hline Iranian Journal Of Parasitology & $\mid Q V / T \& G$ & 0.656 & 1 . \\
\hline
\end{tabular}

بـIranian Red Crescent Medical Journal»

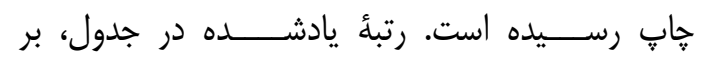

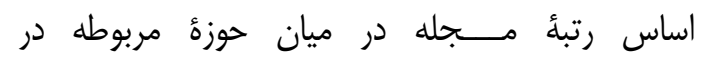

$$
\text { اسكايوس است. }
$$

دادهاى جدول شمارة ب نشان مىدهد كه

بيشترين مقالات دانشگاه به ترتيب در مجلات Journal Of Clinical And Diagnostic »

g «Der Pharmacia Lettre» g «Research"

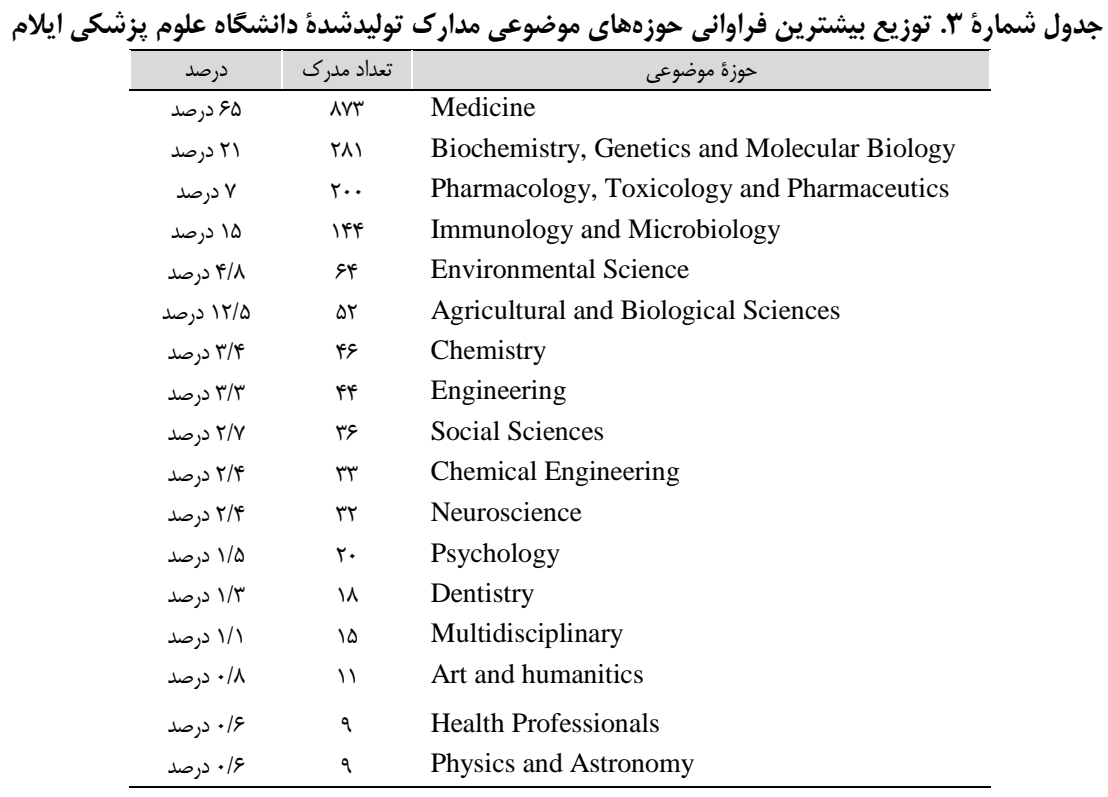

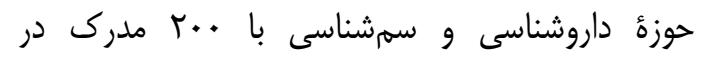
رتبههاى اول، دوم و سوم توليدات علمى قرار دارند.

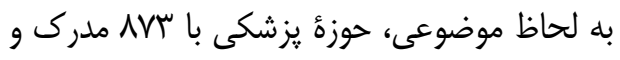

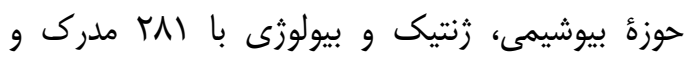




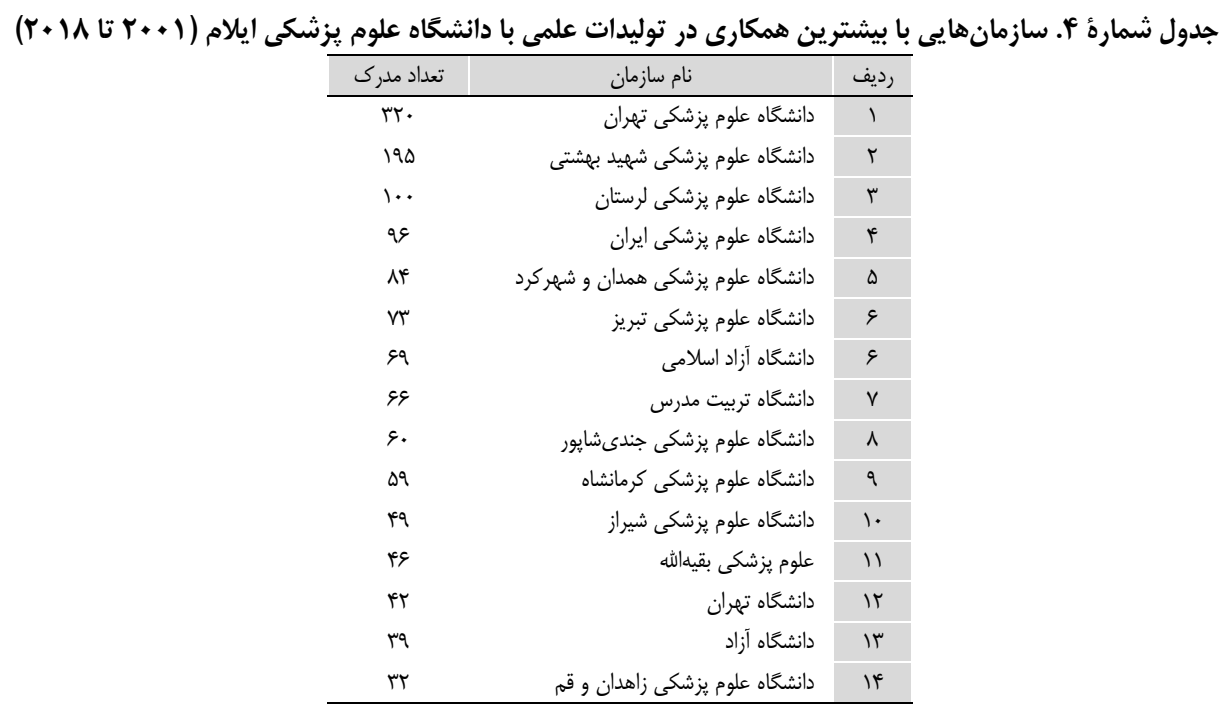

دانشكاه علوم يزشكى ايلام در همكارى با كشور، rDq مقاله توليد كرده است كه آمارهاى

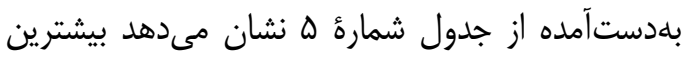

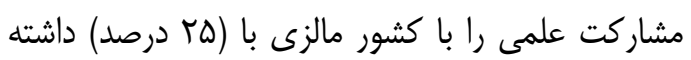

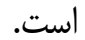

بر اساس اطلاعات جدول شماره عا، دانشعاه علوم

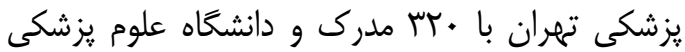
شهيد بهشتى با 190 مدرك و دانشگاه علوم يزشكى

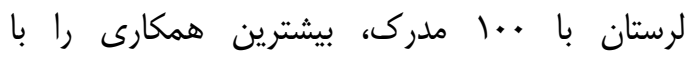
يزوهشگَران دانشخاه علوم يزشكى ايلام داشتهاند.

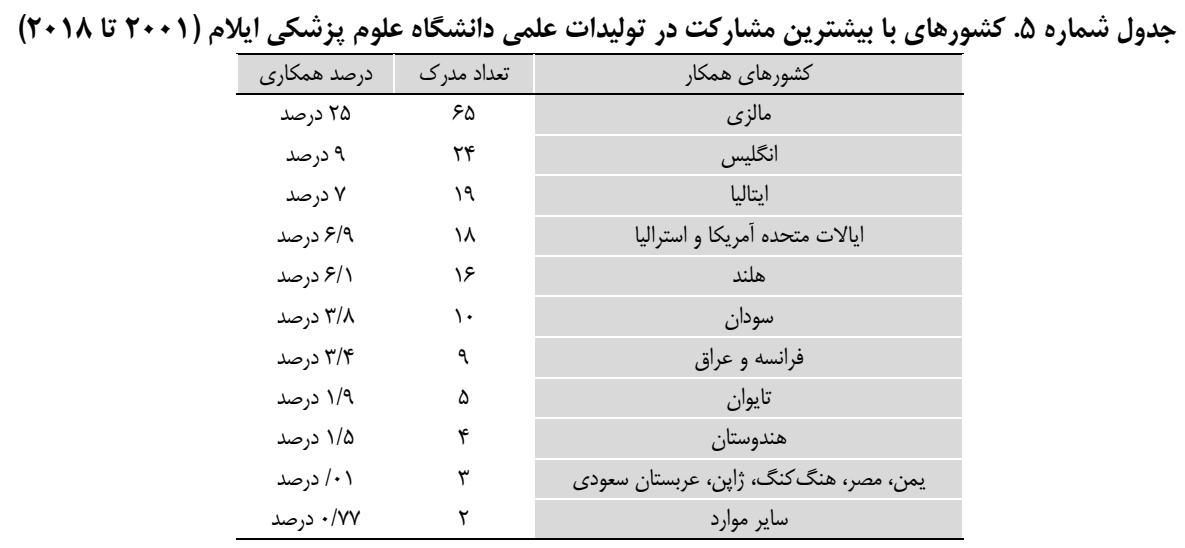

Removal of benzene, toluene, » در جدول شمارء \&، مقالات برتر بر اساس تعداد ethylbenzene and xylene (BTEX) from aqueous solutions by montmorillonite modified with nonionic surfactant: Equilibrium, kinetic and thermodynamic استنادات دريافتشده مشاهده مىشود كه بيشترين تعداد استناد مربوط به سال عزا +r و مقالهاى با عنوان «study با إ. استناد بوده است.

The promise of whole-exome sequencing " «in medical genetics 
جدول شماره و. مقالات يركاربرد دانشَّاه علوم يزشكى ايلام بر اساس فراوانى تعداد استناد

\begin{tabular}{|c|c|c|c|c|c|}
\hline منبع & سال استناد & تعداد استناد & 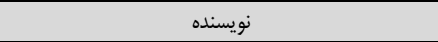 & 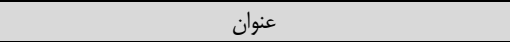 & رديف \\
\hline $\begin{array}{l}\text { Journal of Human } \\
\text { Genetics }\end{array}$ & $r \cdot 14$ & 198 & Rabbani, B., Tekin, M., Mahdieh, N. & $\begin{array}{l}\text { The promise of whole-exome sequencing in } \\
\text { medical genetics }\end{array}$ & 1 \\
\hline $\begin{array}{l}\text { Journal of Human } \\
\text { Genetics }\end{array}$ & $r \cdot i r$ & 1.1 & Rabbani, B., Tekin, M., Mahdieh, N. & $\begin{array}{l}\text { Removal of benzene, toluene, ethylbenzene } \\
\text { and xylene (BTEX) from aqueous solutions } \\
\text { by }\end{array}$ & r \\
\hline $\begin{array}{l}\text { Japanese Journal } \\
\text { of Infectious } \\
\text { Diseases }\end{array}$ & $r \cdot 1$ & १९ & $\begin{array}{l}\text { Feizabadi, M.M., Fathollahzadeh, B., } \\
\text { Taherikalani, M., (...), Soroush, S., } \\
\text { Mohammadi-Yegane, S. }\end{array}$ & $\begin{array}{l}\text { Antimicrobial susceptibility patterns and } \\
\text { distribution of BlaAXA genes among } \\
\text { Acinetobacter spp. isolated from patients at } \\
\text { Tehran hospitals }\end{array}$ & r \\
\hline $\begin{array}{l}\text { Asian Pacific } \\
\text { Journal of } \\
\text { Tropical Disease }\end{array}$ & $r \cdot 14$ & Ar & $\begin{array}{l}\text { Saki, K., Bahmani, M., Rafieian- } \\
\text { Kopaei, M., (...), Bahmani, F., } \\
\text { Asadzadeh }\end{array}$ & $\begin{array}{l}\text { The most common native medicinal plants } \\
\text { used for psychiatric and neurological } \\
\text { disorders in Urmia city, northwest of Iran }\end{array}$ & f \\
\hline $\begin{array}{l}\text { Journal of } \\
\text { Biochemistry and } \\
\text { Molecular Biology }\end{array}$ & $r \cdot .9$ & $v^{e}$ & $\begin{array}{l}\text { Rezaei-Tavirani, M., } \\
\text { Moghaddamnia, S.H., Ranjbar, B., } \\
\text { Amani, M., Marashi, S.-A. }\end{array}$ & $\begin{array}{l}\text { Conformational study of human serum } \\
\text { albumin in pre-denaturation temperatures } \\
\text { by differential scanning calorimetry, } \\
\text { circular dichroism and UV spectroscopy }\end{array}$ & ه \\
\hline $\begin{array}{l}\text { Journal of } \\
\text { Nephropathology }\end{array}$ & $r \cdot 19$ & v & $\begin{array}{l}\text { Baharvand-Ahmadi, B., Bahmani, } \\
\text { M., Tajeddini, P., Naghdi, N., } \\
\text { Rafieian-Kopaei, M. }\end{array}$ & $\begin{array}{l}\text { An ethno-medicinal study of medicinal } \\
\text { plants used for the treatment of diabetes }\end{array}$ & 8 \\
\hline PLoS ONE & $r \cdot 14$ & $s c^{\circ}$ & $\begin{array}{l}\text { Bahadorimonfared, A., Soori, H., } \\
\text { Mehrabi, Y., (...), Salehi, M., } \\
\text { Bakhtiyari, M. }\end{array}$ & $\begin{array}{l}\text { Trends of Fatal Road Traffic Injuries in Iran } \\
(2004-2011)\end{array}$ & v \\
\hline $\begin{array}{l}\text { Archives of } \\
\text { Iranian Medicine }\end{array}$ & 2008 & sc & $\begin{array}{l}\text { Ghazanfari, T., Faghihzadeh, S., } \\
\text { Aragizadeh, H., (...), Emadi, N., } \\
\text { Falahati, F. }\end{array}$ & $\begin{array}{l}\text { Sardasht-Iran cohort study of chemical } \\
\text { warfare victims: Design and methods }\end{array}$ & $\wedge$ \\
\hline $\begin{array}{l}\text { Journal of the } \\
\text { Taiwan Institute of } \\
\text { Chemical } \\
\text { Engineers }\end{array}$ & $r .14$ & 81 & $\begin{array}{l}\text { Noorimotlagh, Z., Darvishi } \\
\text { Cheshmeh Soltani, R., Khataee, } \\
\text { A.R., Shahriyar, S., Nourmoradi, H. }\end{array}$ & $\begin{array}{l}\text { Adsorption of a textile dye in aqueous } \\
\text { phase using mesoporous activated carbon } \\
\text { prepared from Iranian milk vetch }\end{array}$ & 9 \\
\hline $\begin{array}{l}\text { Phytotherapy } \\
\text { Research }\end{array}$ & $r \cdot \cdots$ & $\Delta r$ & Hajhashemi, V., Abbasi, N. & $\begin{array}{l}\text { Hypolipidemic activity of Anethum } \\
\text { graveolens in rats }\end{array}$ & 1. \\
\hline
\end{tabular}

مشاركت خارجى را با كشور مالزى با (هو مدرى) و بيشترين همكارى داخلى را با دانشخاه علوم يزشكى

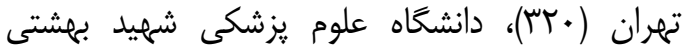
(190) داشته است. از مجموع رrسا مدرك ثبتشده، بيشترين تعداد توليدات مربوط به مقالات اصيل (عنوان (1.91) بوده است. كفتنى است كه ميزان استناد به

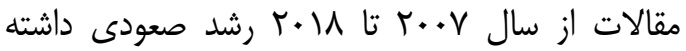
است كه همزمان با رشد توليد مقالات در اين دانشگاه

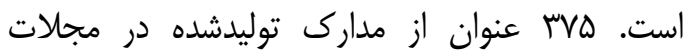
ايناكسس و و سايرين در ديخر مجلات يولى

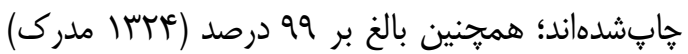
از توليدات، به گُ گاب مقاله اختصاص دارد. در نتايج مشاهدهشه در اسكايوس، در فيلد يرستارى مقالهاى ذكر نشده بود و اين امر به علت جاب نكردن مقاله در حوزة يرستارى نيست، بلكه مىتواند بله اختصاص نيافتن فيلد موضوعى تخصصى يرستارى به مقالات،

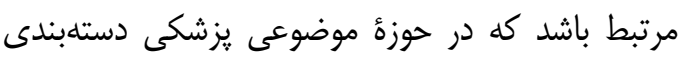
شدهاند. در يزوهش حاضر نشان دادهشده است كه نرخ

\section{بحث و نتيجه تيرى}

نتايج اين يثوهش نشان داد تعداد ثبت مقالات، تعداد استنادات و شاخص هيرش در دانشخاه علوم يزشكى ايلام، در طول دوره مطالعهشده، سير صعودى

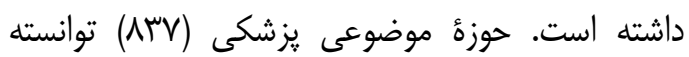
بيشترين رقم توليدات را به خود اختصاص دهد و رشو رشد بالايى دارد؛ همجنين بيوشيمى و زنتيك و فارماكولوزى نيز در ميان ساير موضوعات، سهرم بيشترى از مقالات

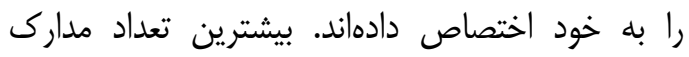

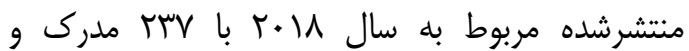

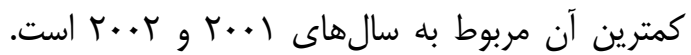
تعداد كل توليدات علمى نمايهشده طى سالهاى ( +..

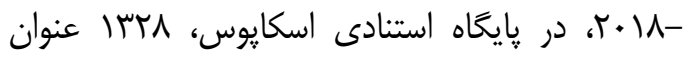
بوده است. از نظر كيفى، مجموع استنادات به مقالات اين دوره سا Vq استناد است كه بيشترين ميزان مجموع

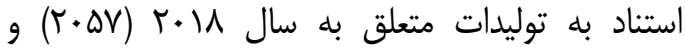

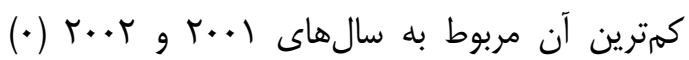
بوده است. دانشخاه علوم :يزشكى ايلام بيشترين 


$$
\begin{aligned}
& \text { حاضر ارائه مى گَرد: } \\
& \text { ا-مقايسٔ كيفى توليدات و تأثير آن بر روند آند بهربون }
\end{aligned}
$$

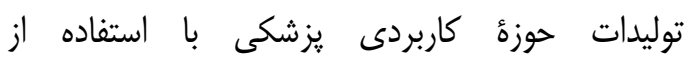

$$
\begin{aligned}
& \text { نرمافزارهاى ييشرفنأ علمسنجى؛ }
\end{aligned}
$$

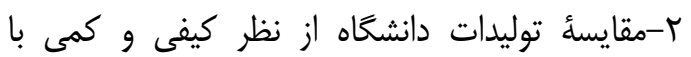

$$
\begin{aligned}
& \text { دانشخاههاى كلان منطقه بلمنظظورافزايش توليدات } \\
& \text { كاربردى و كيفى؛ }
\end{aligned}
$$

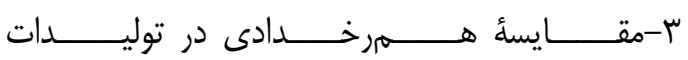

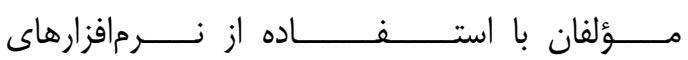

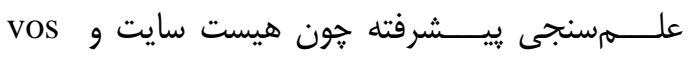

$$
\begin{aligned}
& \text {.viwer }
\end{aligned}
$$

\section{References}

1.FarashbandiF, Heidari G, Osareh F, Hajizein E, Abedini M, Behzadi B. [A study of scientific production in the field of recovering music information]. Sci Res Biolo2017;3: 48-30. (Perisan)

2.Vafaeian A. [Study of the status of scientific production in the field of "Recovering Music Information" at the Scopus site]. Scientometr Res Cent2017; 5:23-8. (Perisan)

3.Jafari F, Tajigol M. [Study of the situation of faculty members of the faculties of humanities art and social sciences of state universities of the country from 2000 to 8. J Sci Technol Res Ins Iran 2012;27: 575-7. (Perisan)

4.Nokarizi M, Alian M. Studying the status of scientific production of faculty members of Birjand University in Scopus base with emphasis on scientific co-operation. Informatics2010; 8: 57-78.

5.Nokarizi M, Zeinali A. [Quantitative analysis of scientific productions of faculty members of ferdowsi University of Mashhad from 2000 to 10]. Lib Info Res2011; 2:73-98.. (Perisan)

6.Mirhoseeini Z, Vahabi F. [In vestigating the scientific productions of Iranian typeI pharmacy faculty members indexed in the

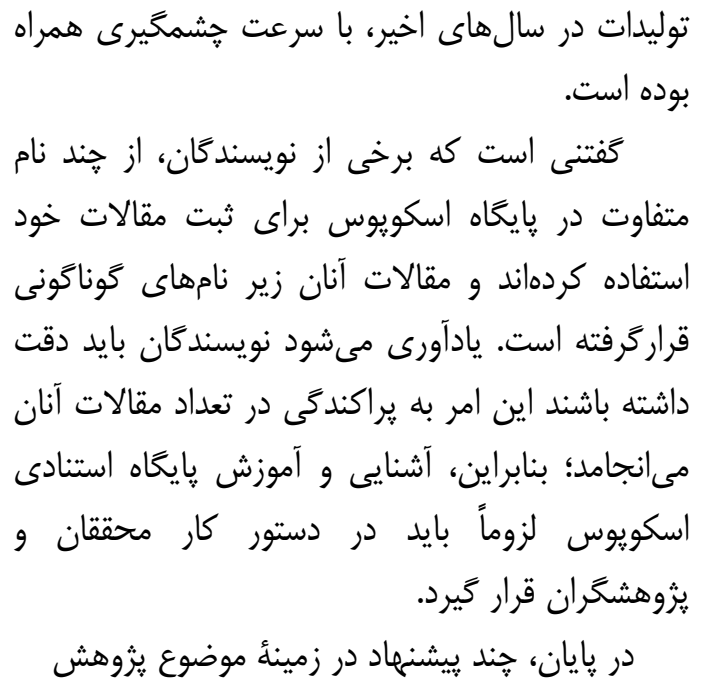

institute for scientific information]. Info Manage 2011; 8: 363-72.. (Perisan)

7. Gomez C, Munoz MT, Gangas M, Morillo Ariza F. La produccion científica espanola e output in medicine in the years 1994-1999]. Rev Clin Esp 2004; 204:75-88. doi.10.1016/S0014-2565(04)71403-4

8.. Bjorn A, Hundrup YA, Wagner L. Doctoral prepared nurses in Denmark and their scientific production between 1976 and 2005. Int Nurs Rev 2008; 55:227-33.

9. Zorzetto R, Razzouk MTB, Gerolin J, Schor N, Guimarães JA, Mari JJ. The scientific production in health and biological sciences of the top 20 Brazilian universities. Bra Med Biological Res2006, 39, 1513-1520

10. Valles J, Perez MD, Osuna E, Luna A. Quantitative analysis of Spanish University scientific output in the area of legal and forensic medicine international exposure. Scientometrics2009;78:383-95. doi.10.1007/s11192-007-1808-2 11. Eyk HJ, Hooiveld MHW, Leeuwen TN, Wurff BL, Craen AJM, Dekker FW. Scientific output of Dutch medical students. Med Teach2010; 32: 231-5. doi.10.3109/01421591003596592 


\title{
A Review of Scientific Products of Ilam University of Medical Sciences from 2001 to 2018 at the Scopus Database: A Descriptive Study
}

\author{
Ranjbar $P^{I^{*}}$
}

(Received: June 1, 2019

\begin{abstract}
Introduction: Evaluation of scientific production plays an important role in planning for the promotion of scientific research centers. This study evaluated the status of scientific products of Ilam University of Medical Sciences, Ilam, Iran, quantitatively and qualitatively from 2001 to 2018 in the Scopus Citation Database.
\end{abstract}

Materials \& Methods: Quantitative indicators, such as the H-index (Hirsch index), and the number of citations to the documents indexed in the mentioned database were utilized to review the indexed medical records of Ilam University of Medical Sciences from 2001 to 2018. It should be noted that the data were collected from Scopus. ISID-indexed articles were also used in this study.

Findings: In total, 1328 articles were submitted during the study period. The highest and lowest rates of submission were observed in $2018(\mathrm{n}=237 ; 17 \%)$ as well as 2002 and 2001 (11.1\%), respectively. The Hirsch index number during these years (2001-2018) was 34. Scientific products
Accepted: February 1, 2021)

were related to the fields of "medicine", "biochemistry, genetics, and biology" and "pharmacology" in descending order. Moreover, the medical field obtained the most citation $(76 \%)$. The highest levels of domestic and foreign participation were with Tehran and Shahid Beheshti Universities of Medical Sciences, as well as academic centers of Malaysia and England, respectively. Furthermore, $88 \%$ of the products of this university were of the original type.

Discussions \& Conclusions: This study revealed a growing trend in the process of scientific production at Ilam University of Medical Sciences, Ilam, Iran. Furthermore, the results of this study showed that from 2013 to 2016 , with an increase of $13 \%$ to $23 \%$, the number of scientific production was significantly higher, compared to previous years.

Keywords: Hirsch Index, Ilam University of Medical Sciences, Scientometrics, Scientific production, Scopus Citation Database.

1. Dept of Scientometrics, Ilam University of Medical Sciences, Ilam, Iran

*Corresponding author Email: rparsi2013@gmail.com 